\title{
THE ART OF TOILET TRAINING
}

C.A. McCormick, M.A. Horan, E.L. Woodward, E.A. Markowski, S. Abdullah, T.-J. McGrath-Daly, A.M. Murphy, J. Meehan, E. Roche

Paediatrics, Trinity College Dublin, Dublin, Ireland

Background: Toilet training is the process of training a child to control their bladder and bowel and to utilise the toilet. It is an essential milestone in a child's development. Limited data exists surrounding normal practices.

Methods: We preformed a comprehensive literature review on training. A random cohort of parents attending an urban paediatrics department were asked to complete a retrospective survey based on their toilet training experiences. Surveying was completed over a seven week period (February- March 2011)

Results: 276 surveys were analysed. The mean age of toilet training initiation was 2.187 years. The mean ages of commencement for children currently over 10 and less than 10 years old was 1.980 and 2.278 respectively, suggesting a pattern of later initiation in recent years $(p<.0001)$. With the exception of learning difficulty, no other factor had a significant difference in age of completion. Average duration was 0.720 years. No aids were associated with a shorter duration of toilet training, though duration in those using specific toilet usage times (mean $=.95$ years) was significantly longer than those not using them (mean $=.42$ years). Approximately $18.5 \%$ of patients reported training difficulties. $75 \%$ of parents used family alone as a source of information/support.

Conclusion: Irish practices largely coincide with those reported in other nations. Our study brought into question some established perceptions (boys are harder to train then girls). Limited support exists for families who have difficulties. Physicians have a poor evidence base on which to make recommendations. 